Pensamiento Crítico N. ${ }^{\circ} 15$, pp. $83-86$

\title{
¿Hacia dónde tiende este proceso de globalización?
}

Luis Mejía M.

\section{RESUMEN}

La globalización está reconfigurando los sistemas productivos: debilita la coherencia de los sistemas económicos nacionales y en el caso de los países subdesarrollados, agudiza al extremo los fenómenos de extroversión y vulnerabilidad. Esto hace que las economías y sociedades nacionales se vuelvan más inestables y desequilibradas.

Palabras clave: Globalización, desarrollo económico, mercado, producción global.

\begin{abstract}
The globalization is re-forming the productive systems: it debilitates the coherence of the economic national systems and in case of the underdeveloped countries, sharpens to the end the phenomena of extroversion and vulnerability. This does that the economies and national societies turn (become) more unstable and unbalanced.
\end{abstract}

Keywords: Globalization, economic development market, global production. 


\section{Pensamiento Crítico N. 15}

El proceso de globalización adquiere un signo distintivo peculiar en dos aspectos: 1) la efectiva transnacionalización de la producción que implica desarticular los sistemas productivos nacionales y "atrapar" la división internacional del trabajo como variable bajo control de los capitales transnacionales; y, 2) los desarrollos inéditos de la esfera de lo financiero. Un tercer elemento se desprende de los dos anteriores: el vínculo entre lo productivo y lo financiero -que sumido en el concepto de capitalismo accionariocomporta un direccionamiento de la producción según criterios de rendimientos financieros, antes que de ganancia empresa.

En ese sentido, podría decirse que estos son tiempos donde la producción queda empapada a profundidad de criterios especulativos bajo los cuales se guía su gestión y organización, no obstante lo cual, lo financiero-especulativo tan solo cuenta con una autonomía aparente. En realidad permanece subordinada a lo que, en última instancia, acontece al nivel de la esfera productiva.

Se ha vivido un proceso de efectiva globalización financiera que, de formar aparente, ha dado signos de autonomía relativa respecto de lo que ocurre en lo productivo. En este último aspecto, la globalización ciertamente ha avanzado más lentamente y sus creaciones son ahí más limitadas. Esto es así en virtud de que la inversión productiva supone una inmovilidad relativa de capitales durante, al menos, el período mínimo requerido para recuperar esa inversión. Pero, en general, la valorización de los capitales productivos supone la vigencia de ciertas condiciones sociales y políticas, además de económicas. Es decir, se sienta en formas institucionales, normativas y culturales que históricamente le han sido proveídos por los Estados-nación. De ahí que aún tenga mucho sentido la identificación de cada corporación transnacional respecto de un Estadonación específico en cuanto este provee esas condiciones para la valorización -y para la protección de sus intereses- no fácilmente sustituibles sobre un plano transnacional. En cambio, la globalización puramente financiera opera sobre indicadores financieros y se guía por criterios uniformes de valoración sin apenas identificación con ningún referente nacional específico.

O, en todo caso, con la identificación mínima necesaria para no dejar de contar, en caso necesario, con el respaldo y protección del poder político y militar de un estado capitalista-desarrollado. 


\section{Luis Mejía Marcatinco}

Sin embargo, la evolución de lo financiero aparece inevitablemente vinculado -y finalmente subordinado- a lo productivo. Primero, porque es el desarrollo en lo productivo, en particular las tecnologías de la información lo que da la base objetiva que potencia e impulsa la globalización financiera, y sin el cual ésta jamás habría alcanzado el desarrollo hipertrofiado que muestra.

Segundo, y fundamentalmente, porque cualquier expansión financiera que supere los límites que demarca la esfera de lo productivo entra en el terreno de lo puramente ficticio y está condenado a su disolución. Ello es lo que una vez más han demostrado las crisis financieras de los noventa y primeros años de los dos mil y el derrumbe de las bolsas en 2000-2003. Finalmente, este crecimiento financiero solo es posible si existe un contexto político propicio que dé lugar a formas institucionales y normativas de alcances tendencialmente globales, sobre cuya base canalizar tal proceso. Es decir, y en contra de la visión alucinada de una globalización financiera sin ataduras, lo cierto es que esta solo es posible porque existen las condiciones políticas que le proporcionaron tales condiciones de posibilidad.

\section{Condiciones de posibilidad}

El desarrollo bajo la hegemonía estadounidense del sistema creado en Bretón Woods dio forma, en sus etapas embrionarias, a lo que hoy día es una globalización financiera asentada en mercados carentes de cualquier ancla institucional. Aún White y Keepres -artífices originales de este sistema- previeron que debían existir controles que regularan la derivada de los capitales, lo cierto es que, asentado en su incontestable predominio, Estado Unidos promovió ya desde los años cincuenta un sistema mundial abierto a los flujos de capital. En ese contexto, los euromercados inicialmente encontraron terreno propicio donde florecer.

Este desarrollo de la esfera de lo financiero ha sido posible no tan solo porque existan desarrollos tecnológicos que lo posibilitan. Esa es una parte de la cuestión

y, ciertamente, la más evidente. Los desarrollos de la informática, la alternativa y las telecomunicaciones proporcionan un soporte material, sobre el que se levanta el desarrollo de la interconexión instantánea entre todas las plazas financieras del mundo. Esto, desde luego, acelera el ritmo febril de los negocios especulativos. 


\section{Pensamiento Crítico N. 15}

Sin embargo, existen condiciones de orden político y económico fundamentales que son, asimismo, requisitos necesarios para que esta explosión especulativa tenga lugar. Las condiciones políticas tienen que ver con la seguidillas de decisiones que, a lo largo de varias décadas, se han ido imponiendo a nivel mundial para la creación de un sistema financiero desregulado.

La especulación adquiere el ímpetu que hoy muestra y que se convierte en una potencia que tiende a abarcar todo arrastrando incluso a los capitales que predominantemente se suponen retirados en el ámbito productivo. La especulación es consustancial a este capitalismo de la actual globalización, en virtud de su sesgo unilateral hacia la rentabilidad fácil y las variables financieras, con olvido de la dimensión humana de la realidad social. En tales rasgos se manifiesta la realidad más profunda de esta globalización neoliberal.

\section{Bibliografía}

CRECIMIENTO ECONÓMICO (2001). Editorial Alfaomega.

EITEMAN DAVID K. (1998). Las finanzas en las Empresas Multinacionales. Editorial Prentice Hall.

Revista de Fondo Monetario Internacional

FINANZAS Y DESARROLLO. Junio 2002

Revista de Fondo Monetario Internacional

FINANZAS Y DESARROLLO. Setiembre 2002

Revista de Fondo Monetario Internacional

FINANZAS Y DESARROLLO. Marzo 2004

Revista de Fondo Monetario Internacional

FINANZAS Y DESARROLLO. Marzo 2009

Revista de Fondo Monetario Internacional

FINANZAS Y DESARROLLO. Junio 2002

FINANZAS PARA EL CRECIMIENTO ECONÓMICO. A World Bank Policy-Reasearch Report.

YIP GEORGES S. (1992). Globalización. Editorial Norma. 